\title{
Más allá del duelo, otras formas de imaginar, sentir y pensar la memoria en Centroamérica, de Yansi Pérez ${ }^{1}$
}

Yansi Pérez nació en El Salvador, pero emigró a temprana edad a los Estados Unidos. Se radicó en Nueva York. Allá tuvo la oportunidad de seguir estudios superiores en prestigiosas universidades. Obtuvo una licenciatura en Literatura Comparada en la Universidad de Stanford, asimismo, su maestría y doctorado en Lenguas y Culturas españolas y portuguesas en la Universidad de Princeton. Su tesis doctoral fue defendida en 2007 y versó sobre Roque Dalton, trabajo que luego se transformó en un libro que lleva por título: La poética de la historia en la obra de Roque Dalton. Hace unos años recibió una beca de la Mellow Public Works Grand and Broom Fund, para realizar una investigación sobre la memoria de la diáspora salvadoreña en la ciudad de Los Ángeles. Entiendo que esta investigación servirá de base
Ricardo Roque Baldovinos Universidad Centroamericana "José Simeón Cañas", UCA

para un nuevo proyecto de libro que tiene en preparación con el título: $L a$ experiencia de la migración salvadoreña: memorias transnacionales de la diáspora.

El libro Más allá del duelo, otras formas de imaginar, sentir y pensar la memoria en Centroamérica reelabora algunos de los muchos ensayos académicos que su autora ha presentado en congresos internacionales y posteriormente publicado en revistas de prestigio en sus áreas de conocimiento. Como vimos, la formación de Yansi Pérez fue en literatura, pero Más allá del duelo no es un libro sobre literatura en el sentido que estamos acostumbrados como un tipo de libro que tiene por cometido exponer alguna obra, autor o período; más bien, es un libro sobre un problema que excede lo literario, la memoria, pero 
donde lo literario está presente no sólo como objeto sino también como estrategia de literatura. Sabemos que una cuestión central en la memoria es la manera en que ésta se narra; de esta manera, la literatura ha jugado un papel central en evidenciar las dificultades en este trabajo de narración. Es cierto que este libro recoge otra serie de expresiones culturales que también lo han intentado, como el cine, el video-arte o, incluso, las narrativas mediáticas. Pero decía que la literatura juega un papel importante como estrategia de lectura, pues uno de los méritos de este libro es mostrar cómo la interpretación de los textos sociales puede beneficiarse de una lectura atenta y cuidadosa, que toma en cuenta el poder de la forma, del género discursivo y que no es otra cosa que una práctica social cristalizada, como lo mostró en su momento Mijaíl Bajtín.

El libro plantea que para entender el problema de la memoria es necesario ir más allá del duelo, figura que dominó el debate sobre la memoria en los procesos de transición democrática en América Latina. La figura del duelo se establece en una genealogía que parte de Sigmund Freud y Walter Benjamin, en Europa, y aterriza en los debates sobre la memoria en América del Sur con trabajos pioneros como los de Idelber Avelar o Elizabeth Jelin.

Sin embargo, según Yansi Pérez, las condiciones propias de los conflictos armados de Centroamérica (particularmente los de Guatemala y El Salvador, a los que dedica mayor atención en su libro) y también las condiciones de la posguerra, involucran otras apuestas y movilizan otros afectos. Por dicha razón, la memoria se narra recurriendo a figuras muy diversas que Yansi intenta analizar a lo largo de los distintos capítulos del libro. Al hacerlo, Yansi no sólo sitúa esos textos en las condiciones concretas de Centroamérica, sino que lo logra haciendo gala de una muy inteligente erudición, de tradiciones literarias que se remontan muy atrás en la historia, al siglo XIX o incluso a la era clásica. No haré un inventario muy exhaustivo, sólo señalaré que en esta dirección me parecen ejemplares los dos primeros capítulos, en los que destaca dos tradiciones: el relato de un crimen (la novela policial, pero que va más atrás) y las metamorfosis.

Muchos trabajos como los de Misha Kokotovic o Uriel Quesada señalan la importancia que tiene una relectura del género policial en Centroamérica, pero Yansi amplía ese marco de discusión al relato del crimen. Aquí echa mano de la idea de Piglia sobre el Estado como una maquinaria paranoica y sobre la barbarie y violencia que subyace nuestras historias. El crimen develado no se limita a restituir el orden roto, sino a poner en evidencia que ese es un eslabón en una cadena mucho más amplia de iniquidades del tejido social, lo que desde el vocabulario de la teología de la liberación se llamó 
el pecado social y el padre Ellacuría lo denominó como el mal común.

Otra avenida de diálogo muy interesante que propone el libro es la que plantea sobre los relatos de transformación donde los personajes dejan su forma humana y se transforman en animales. Al respecto, vale resaltar los cuentos de Claudia Hernández o de Jacinta Escudos. Estos trabajos han dado lugar una serie de lecturas desde el debate contemporáneo en torno a lo poshumano. Nuestra autora sitúa estos relatos en una perspectiva más amplia y de larga duración. No sólo está el evidente antecedente de la célebre nouvelle de Kafka, sino la metamorfosis como género de la literatura clásica (a la manera de Las metamorfosis de Ovidio), pero también como figura presente en las más antiguas tradiciones orales. Yansi Pérez sigue, en este sentido, a Lévi-Strauss cuando señala que la frontera entre lo humano y lo no humano (animal, vegetal y mineral) es constituyente del sistema de valores de una sociedad y que, por tanto, su transgresión permite explorar y poner en discusión sistemas de normas y valores que se agrietan ante realidades fluidas y cambiantes. Se extrapola así la metamorfosis no sólo a personajes que se transforman en animales, como sucede en los cuentos de Hernández o Escudos antes señalados, sino a los protagonistas de relatos de mutilación, donde ellos se ven forzados a sentir y pensar nuevamente la relación de sus cuerpos con el mundo y con los otros. Este último es el caso del protagonista de la novela El cojo bueno de Rodrigo Rey Rosa, el cual sufre la amputación de su pierna, pero este trauma lo obliga a caer en la cuenta de que su condición de privilegio lo convierte también en parte del mundo de los victimarios, en una sociedad agobiada por la desigualdad y la injusticia. Así se logra explicar el enigmático final de la novela, donde el protagonista al renunciar a la venganza, no sólo logra reencauzar su propia vida sino vislumbrar un camino para destejer la trama de odio en que se encuentra enredado su país.

También quiero destacar la lectura que Más allá del duelo nos entrega del documental El lugar más pequeño, de Tatiana Huezo, y de su forma original de narrar el trauma y el horror; es una forma indirecta que se rehúsa a mostrar los cuerpos de los muertos o de hacer planos de los sobrevivientes en el momento de narrar sus historias más dolorosas. Huezo emplea, en cambio, recursos oblicuos como la voz fuera de campo, o el contraste entre el dolor de la voz y la belleza de la imagen. Estos recursos apuntan hacia estrategias de asumir sin escamoteos el dolor y la pérdida, pero también de afirmar la vida como fuerza que sigue y de la que participan plenamente estos protagonistas en su comunidad recuperada.

El trabajo termina con un homenaje a la política de la memoria que fuera de los espacios oficiales 
ha venido reconstruyendo el Museo de la Palabra y la Imagen. Una memoria que no cae en la idealización del pasado que sustenta los privilegios de unos y que tampoco repite la narrativa revolucionaria tradicional; es una memoria incluyente, pero sobre todo, una memoria cargada de futuro que se imagina otro país posible a través de un público imaginado que actualiza mediante las prácticas museográficas innovadoras.
El libro de Yansi Pérez es una contribución oportuna a los debates sobre la memoria que en los últimos años han cobrado renovado interés en nuestro país, luego de varios lustros de olvido institucionalizado. Nos recuerda que la memoria no sólo tiene que ver con la correcta construcción del pasado, sino con la inmensa tarea que tenemos delante de construir un país que asuma su pasado, tanto en lo que carga de oprobio como de esperanza.

\section{Referencias bibliográficas}

Avelar, I. (2000). Alegorías de la derrota: La ficción posdictatorial y el trabajo del duelo. Santiago de Chile: Editorial Cuarto Propio.

Jelin, E. (2019). State Repression and the Labors of Memory. Minneapolis: University of Minnesota Press.

Kokotovic, M. (2006). Neoliberal Noir: Contemporary Central American Crime Fiction as Social Criticism. Clues, 24.3, pp. 15-29.

Pérez, Y. (2019). Más allá del duelo, otras formas de imaginar, sentir y pensar la memoria en Centroamérica. San Salvador: UCA Editores.

Quesada, U. (2012). ¿Por qué estos crímenes? Literatura policiaca en Centroamérica. En Cortez, B. , Ortiz Wallner, A. y Ríos Quesada, V. (Eds.), (Per)Versiones de la modernidad. Literaturas, identidades y desplazamientos. Guatemala: F\&G Editores.

\section{Notas}

1 Este texto reelabora la presentación del libro que tuvo lugar en la Librería de la UCA, el 16 de agosto de 2019. 